\title{
Analysis of the Grammatical Passive Voice in English and Chinese, a Comparison between the Two Languages
}

\author{
Amerigo Quatrini \\ Shanghai University, School of Foreign Languages, Shangda Rd 99, Shanghai, China
}

\begin{abstract}
The usage of the grammatical passive voice in English and Chinese is analyzed and investigated by this study, making a comparison of the two different approaches Chinese and English have. When using a different language, different rules and customs are bound to appear, hence a different form of the passive voice with its different rules and usages is very likely to appear as well: this research highlights the differences between the two language and gives and insights for learners of either language. The reasons why the passive voice is used in both language and how are explained. The main features of both passive voices are also described.
\end{abstract}

\section{INTRODUCTION}

$\mathrm{W}$ hen talking about language and its usage, there are many details to be put into consideration; being a language composed by its own rules and conventions, and therefore speaking habits, a language even when it belongs to the same family, might have different characteristic. This is the case for every language in the world; each language is a unique concoction of rules and features that only belong to that specific one. This of course, applies to specific grammatical rules as well then. The main focus of this paper is the passive voice, in the specific the passive voice of the English language, and the passive voice of Standard Mandarin Chinese.

\section{Motivations of the study}

The present study focuses on Mandarin Chinese and English, reason being the two languages are two of the mostly spoken languages in the world; not only that, but as a non-native speaker of both, I personally encountered difficulties when switching from active to passive in both languages, especially when translating from one to another. This issue seems to be very common among Chinese speakers and English speakers as well; this research aims to highlight when this happens, as well as explaining how this phenomenon occurs.

\section{Significance of the Study}

Despite the countless research on the matter, non-native speakers of English and Chinese still struggle to successfully translate meaning in their second language (from now on abbreviated as L2; first language will be abbreviated as L1) passive form. This issue, though it does not affect communication, still manages to create confusion and misunderstandings. As such, it is worth investigating on how to tackle the problem and how to improve the use of passive form in either language.

\section{Overview of the Thesis}

The passive voice is defined as a grammatical structure that is common to many languages around the world. The passive voice, in contrast to the active voice, is structured in a way that makes the subject being the object of the action or the effect of the verb. To take a simple example "The landscape was painted by Tony" would be the passive voice of "Tony painted the landscape".

Focusing on English and Mandarin, the two languages belong of course to two different language families; English is an Indio-European language that evolved from the branch of medieval West-Germanic languages (Aarts et al. 2006); Modern Mandarin Chinese is a Sino-Tibetan language that presumably originated in Eastern Asia. The two languages already have not much in common. Is that the case though? As today, English is spoken by more than 1.132 billion people globally - both native and non-native speakers - and over the years has become the lingua franca of the world (Eva. 2016). Standard Mandarin Chinese, from now abbreviated to just Chinese, is spoken by about 1.116 billion speakers and has been slowly becoming a new language of the business world with more than 200 million of people studying Chinese as second or third language (Hanban statistics, 2020). Both English and Chinese cover a very important economic and political role then, making them so far different but at the same time so similar. The similarities between the two languages don't end here though, linguistically speaking both languages follow the subject-verb-object (SVO) structure, a structure shared by $42 \%$ of languages in the world (Luke er al. 2010). This SVO structure might also imply that the two languages passive voice might be similar, but this unfortunately - is not the case.

In the following chapters how the passive voice of both languages works will be analyzed and explained, as well as how they differ and what are the similarities of the two.

\section{LITERATURE REVIEW}

The passive voice has been the main topic of many linguistic researches throughout the years, and the comparison between different passive voices has been debated thoroughly as well. 


\section{Definition of Passive Voice}

The passive voice, as mentioned in the previous chapter, is a grammatical structure found in many languages across the globe. With the term voice, linguists refer to a grammatical category that describes the relationship between certain actions and their arguments (Murray and Rockowitz). Beside our main topic - the passive voice - there are many other voices that might appear in certain languages, the most common being the active voice, and less common adjutative voice, antipassive voice, applicative voice, causative voice, circumstantial voice, impersonal passive voice, mediopassive voice, middle voice, neuter voice, reciprocal voice and reflexive voice. Some of these less common voices, are present only in language that are not spoken by many people and therefore unknown to most, linguists included ((7) O'Grady et all, 2001).

The passive voice, as the name implies, is in direct contrast with the active voice, the voice that we usually utilize in SVO languages. In Indo-European languages, the passive voice in characterized by the subject not being the agent, or the initiator of a certain action, but the object being the agent and not the patient instead. There is usually a change of words in the sentence, in some case a change of verb tense, a change in the form of the noun used and an overall use of specific verbal morphology. A passive voice of a language can also have distinct characteristics when used in different grammatical contexts; the passive voice can be declarative, when it states a fact directly; interrogative, when the sentence asks a question; imperative, when the sentence implies a direct order or command. The passive form could also describe a specific circumstance or context, emphasizing on the subject and its relation with the action, the verb.
a. Declarative
My cake has been eaten
b. Interrogative
Was my cake eaten?
c. Imperative
Let the cake be eaten!
d. Gerundial
Emma likes being photographed

According to linguists (Pullum, 2011) the passive voice can be either dynamic or static, the former referring to a sentence where the main action is being performed by something or someone; the latter referring to a state of the sentence, a condition or a characteristic of it.

a. The hair is being cut. Dynamic passive voice.

The hair is being cut by someone or something.

b. The hair is cut. Static passive voice.

The hair is cut refers to a specific state of the subject.

Another interesting feature of the passive voice, is the fact that it can be used with any verbal tense in most languages, and as we have seen earlier, the passive voice could be expressed in many different ways, according to the contexts and motives.

\section{When to use the passive voice}

As when to use the passive voice the answer might require a bit of mind flexibilities. Simply said, the passive voice is generally used to emphasize the object of a sentence instead of the subject, but this sort of simplified explanation does not cover fully the real scope of the passive voice. Generally speaking, the passive voice allows for a large flexibility in sentence construction and gives the speaker, or the writer, the opportunity to emphasize a certain clause over another. In the field of linguistics, the term passive is applied to a range of grammatical structures that could be defined as very wide, therefore linguists might find it difficult to define the term in a universal way that that could make sense across all languages in the world and therefore might be hard to highlight when to use the passive voice in the specific and in a universally acceptable manner. The passive voice can be used to de-emphasize an unknown agent of the sentence and making the object the only participant of the sentence.

a. The water was spilled.

In this sentence it is not possible to determine who performed the action, who spilled the water; the only information given is that this action happened and only the result of the it is known. In this sentence the subject is being omitted and it is not important to the situation; someone spilled the water, but this someone is not being accounted for the action itself, making the result - the water being spilled - the only important information conveyed by the sentence.

\section{Empirical Studies in the West}

According to J. I. Saeed, the passive voice allows the speakers of English to utilize a great flexibility in viewing thematic roles. Using the passive voice might allow the speaker to describe the point of view of the patient rather than that of the agent, giving the sentence a different emphasis that might change its core meaning. Saeed also argues that in some case the passive voice can be used to obscure the identity of an agent and being then just implied, without having the necessity to talk about the agent itself anymore. In some other cases, Saeed demonstrates how the changing of word order can lead to a change of meaning and, according to the context, might change the main purpose of the sentence itself.

A. M. Baratta in Revealing stance through passive voice, Journal of Pragmatics, 2008, highlight the importance of the passive voice and how writers could use it to maximize their writing. Baratta argues that even though the passive voice is generally used to either conceal information or to emphasize information to other's expense, it could be used to help the writer to talk about their opinion in an objective detached way. The passive voice is generally thought to be used to maintain a cold detachment in writing, but in reality, it offers a large flexibility of meanings that could be used to the writer's advantage. This is also important to understand how the passive voice covers an important role in the English language.

Smollett and Corson defined the guidelines of the use of the passive voice in the English language, and these guidelines might be helpful to students of the languages and even native speaker, making sure the understanding of the passive voice and 
its grammatical feature will not be misunderstood. The fact that there are specific rules to follow make mastering the passive voice a more complex task than previously thought. Learners of English that approach the passive voice blindly might encounter difficulties as well as misunderstandings.

\section{THE PASSIVE VOICE IN ENGLISH}

It is finally time to analyze in details the passive voice of English Language. As we have seen earlier in the previous chapters, the English language possess a very flexible passive voice that can be used in combination with all verb tenses, as well as being used to express and convey a wide range of meaning and contexts. The passive voice of English follows a set of very simple rules; to form the passive voice it is only necessary to switch the word order - subject/object - and use the auxiliary verb to be. In some cases the auxiliary verb to let and the auxiliary verb to get are also used.

When forming a passive sentence using a simple verb tense our main concern is whether the verbs are being used correctly and whether the auxiliary verb is placed in the correct grammatical position. The sentence structure remains the same.
a. Active voice: to eat
I eat an apple
b. Passive voice: to be eaten
An apple is eaten by me

This is most basic sentence structure the passive voice can produce; as shown in the examples, the auxiliary verb to be cover a very crucial role in the passive voice and determines how the sentence will be converted from active to passive. When converting active to passive though, grammatical changes of the verbs must be considered as well; is eaten correspond to the active I eat but the two verb tenses are actually different. Is eaten is from by the auxiliary verb to be in its present simple form is plus the verb to eat in its past particle form.

Let us leap into the realm of the to get passive voice; when forming a sentence using the get-form it goes as it follows.

a. I eat an apple

b. The apple gets eaten by me

The same structure [auxiliary verb] + [past particle] appears in this structure as well, the only notable difference is of course the use of the verb to get instead the verb to be. This structure is to be considered less formal and more dialectical than the previous one, as by rule to get verbs (get killed, get robbed, get shot, get paid) are usually specific verbs that already appear to be formed by the auxiliary get and their past particle forms; therefore verbs that are not usually in couplet with to get are used mostly in spoken English as they might be considered mistakes in in the written form.

The third form of passive voice is the one composed by the auxiliary verb to let. This form of the passive voice has an imperative meaning to it; therefore, it might contain a command or an order.

a. Let me eat the apple b. Let the apple be eaten by me

If the auxiliary to let is used, the main meaning of the sentence might change drastically. I eat an apple/an apple is eaten by me only describe the action of an apple being consumed, while adding to let shows an imperative scope; let me - allow me, give it to me.

\section{When to use the passive voice in English}

The passive voice is widely used in the English language, such so that in some cases scholars suggest not to use it so often in written English. In the case study The Correct Use of Passive Voice in Report Writing by Somali SPACE Students in UTM, majority of the students were found unable to use the passive voice correctly and in the appropriate context.

In the case of Chinese students learning English as a second language, students often struggle with the English passive voice and the relative translation into Chinese (Liu and Jin, 2011). This difficulty of translation will be analyzed in the following chapters.

As to when to use the passive voice in the English language, according to professor T. Corson and professor R. Smollett from the University College Writing Centre of the University of Toronto, there are 6 specific situations where the passive voice is encouraged and should be used instead of the active. (Corson and Smollett, 2019)

1. The actor is unknown:

a. The cave paintings of Lascaux were made in the Upper Old Stone Age.

2. The actor is irrelevant:

b. An experimental solar power plant will be built in the Australian desert.

3. You want to be vague about who is responsible:

c. Mistakes were made.

4. You are talking about a general truth:

d. Rules are made to be broken.

5. You want to emphasize the person or thing acted on.

e. Insulin was first discovered in 1921 by researchers at the University of Toronto.

6. You are writing in a scientific genre that traditionally relies on passive voice.

$f$. The sodium hydroxide was dissolved in water. This solution was then titrated with hydrochloric acid.

Since there are contexts where the passive voice is preferable, therefore there must be occasions where the passive voice should not be used. According to Corson and Smollett, the passive voice should be avoided when a passive sentence could have a vague meaning or a non-specific agent or actor, making the sentence grammatical correct yet easily misunderstood. 
a. The cellphone was invented in the early 80 's.

Who invented the cellphone though? This information is lacking and it might be needed.

\section{THE PASSIVE VOICE IN CHINESE}

The passive voice in Chinese is not as frequently used as in English and being so the case, the passive voice in Chinese appears to be not as flexible as the English counterpart. It must be noted though, that the passive voice at the same time is a key feature of the language; not being used that often does not mean the passive voice does not cover an important role in the Chinese language. The passive voice in Chinese is structured really simply and follows a very straightforward rule.

a. [noun] + 被 (bèi) $+[$ noun] $+[$ verb]

This is the fundamental structure that the passive form must abide to; in some cases, there is also the option of omitting the second noun that usually plays the role of object.

a. “我父亲被狗咬了(wo fuqin bei gou yaole)”

My father was bitten by a dog.

This very basic sentence shows how the passive is being used in Chinese and show us how the structure follows a sole rigid rule. In this specific sentence the subject is placed before the co-verb particle 被 (bei), while the subject just follows right after, and then the verb, which does not change since Chinese does not have conjugations. This sentence translated word by word in English, would roughly be "my father by a dog bitten was", which is grammatically correct but to a native English speaker could sound slightly odd.

The co-verb particle 被(bei)

To now dig deeper in the rules of the passive voice in Chinese, it is needed to explain what 被 (bei) is.

被 (bei) is a co-verb particle, a particle that cooperate with the verb and therefore modifies it, but that cannot be used by itself. This means that 被 (bei) cannot be used in such a sentence

a. “我被了 (wo bei le)"

The sentence above does not mean anything in particular and the reason is because the sentence is indeed incomplete: it lacks of a verb and a predicate. 被 (bei) then has both the function of modifier of the verb as well as becoming part of the subject when translated in English. Let us take another example to explain this; the famous Na Ying's song 征服 (zhengfu) goes:

a. 就这样我被你征服 (jiu zheyang bei ni zhengfu)

I was conquered by you just like this.

我被你征服 (wo bei ni zhengfu) literally translates into “I, by you, was conquered". This is a very good example to show the function of 被 (bei) and understand how to utilize it. I was conquered, 我被 [object] 征服, in this clause 被 is part of the predicate, it is indeed the modifier of the verb. 被你, by you, in this case the particle 被 is part of the object.

\section{Historical usage of the passive voice}

Beside 被 (bei) there are also other means to create a passive sentence in Chinese, and in these cases also the use of co-verb particles is fundamental. 让 (rang), 叫 (jiao), 受 (shou), and 为 (wei) can also be used to form a passive clause in Chinese. 让 (rang) is usually a verb but can also be used as co-verb particle to make a passive sentence. An example of this is the following sentence:

a. 那件事让他办好了 (na jian shi rang ta banhaole)

\section{That matter has been dealt with by him}

Even though 让 (rang) can be used as passive marker for the passive voice in standard mandarin Chinese, 被 (bei) is preferable. This is because the particle 让 could be confused with the verb 让 (rang) (meaning to let, allow, permit). 让 is then mostly used as a verb, for instance 让我拿一下 (rang ta nayixia), let me take it, 请让他自己解决问题 (qing rang ta ziji jiejue wenti), please allow him solve the problem by himself.

Another particle that can be used to form the passive voice is 叫 (jiao). 叫 (jiao) serves the same exact function as 被 (bei) and 让 (rang), but it has a different meaning when taken by itself as a verb, 叫 (jiao) means to call, to order, to ask when taken in its verb form.

a. 钱叫人偷了 (qian jiao ren toule)

The money was stolen by somebody

The sentence above has the same meaning of “钱被人偷了 (qian bei ren toule)". The only downside of using 叫 (jiao) instead of the regular form 被 (bei) would be once again the fact that it could be confused by the interlocutor and create misunderstandings.

In addition to 被 (bei), 让 (rang) and 叫 (jiao), in northern China the verb 受 (shou) is used instead. This is a mere colloquialism used in norther dialects and does not represent standard Mandarin Chinese.

a. 钱受小偷儿偷了 (qian shou xiaotouer toule)

\section{The money was stolen by a thief}

Lastly there is another way to form a passive voice in Chinese, but it is considered antiquate and obsolete by modern standards; the particle 为. Using 为 to form passive sentences used in ancient Chinese and not used anymore in modern Chinese.

a. 父母宗族, 皆为翏没 (fumu zongzu, xie wei lu mei)

My parents and my clan were all killed.

In modern Chinese this sentence would translate into 父母及 族人, 都被杀死了 (fumu ji zuren, dou bei sha sile), where 被 
(bei) is used instead of 为 (wei).

In the poem 项羽本纪 (Xiangxi benji) historian Sima Qian uses the ancient form of the passive voice as it follows:

江西皆反, 此亦天亡秦之时也。

吾闻先即制人，后则为人所制。

吾欲发兵，使公及桓楚将。

(jiangxi jie fan, ci yi tianwang qin zhi shi ye.

Wu wen xian ji zhi ren, hou ze wei ren suozhi.

Wu yu fabing, shi gong ji huan chu jiang)

Jiangxi rebelled. It's time for heaven to destroy the Qin Dynasty.

I heard that people could subdue others in ancient times, and then they would be made by others.

I want to send troops and send Zhao Gong and the general of Huan Chu army.

In here it is shown how 为 (wei) is used in the middle sentence “吾闻先即制人, 后则为人所制 (Wu wen xian ji zhi ren, hou ze wei ren suozhi)" and it would translate into modern Chinese as “我知道只有先发制人才能让自己占得先机, 否则 就会被他人所制约使自己受制于人 (Wo zhidao zhi you xian fazhi rencai neng rang ziji zhan de xainji, fouze jiu hui bei taren suozhi yueshi ziji shouzhi yu ren. ”, I know that only by taking the initiative can I get the chance, otherwise I will be restricted by others and be controlled by others. This form of passive voice is not being used in modern Chinese any longer, hence most of the Chinese speakers might have problem understanding it, but learners of ancient Chinese and Chinese literature will of course know the structure and its meaning.

When to use the passive voice in Chinese

As explained above, the Chinese language does have a passive voice and how it is structured, it is time to understand how and when to use it. There are some rules attached to such grammar composition and as with its English counterpart, it must be used in certain contexts and situations. The Chinese passive voice does have a strict sole rule for its composition, and so it is expectable to also have strict rules for its usage. First of all, the passive voice in Chinese is mostly used to describe a negative matter or situation; for instance, "my wallet was stolen" translates into Chinese 我的钱包被拿走了 (wode qianbao bei nazoule) directly while a positive matter prefers the use of other grammatical structures. A simple example is the sentence "the meal was cooked by him" that in English uses the passive voice, but in Chinese would sound odd, 饭被他做完了 (fan bei ta zuowanle). To fix the issue the sentence should be converted back to the active voice.

a. 饭被他做完 (fan bei ta zuowan)

He has finished cooking the meal Wrong b. 他把饭做完了 (ta ba fan zuowanle)

He has finished cooking the meal Correct

While translating from English to Chinese, it must be considered that 被 (bei) cannot be used to describe a positive sentence and so a different modifier should be used, in the specific case the co-verb 把 (ba). English to Chinese translation difficulties will be analyzed in the following chapter.

\section{COMPARISON OF THE TWO DIFFERENT FORMS OF PASSIVE VOICE}

English and Chinese are two languages that are structurally different when it comes to the passive and active forms of speech, let us analyze some specific cases of how the passive form is preferred in English while the active is used in Chinese. In English the passive voice is very commonly used as we have seen already, and it can juggle among different tenses and semantic topic very agilely. Unlike English though, Chinese usually tends to use the active voice instead, being its passive voice ruled by a strict context.

\section{Translating the English passive voice into Chinese}

Both English and Chinese use the active and passive form in different ways to convey and emphasize different meanings, and therefore put a stress on certain clauses over others. Below we will analyze a series of common sentences used in both languages and see how the translation from English to Chinese might arise some difficulties.

a. Tea is drunk widely all over the world

This sentence clearly uses the passive voice to express and convey that all around the world tea is being drunk, or in the active voice people drink tea all around the world. This emphasizes the word tea, making it the main topic of the sentence. If we were to try translating this sentence to Chinese directly, we would make a rooky mistake. Translating this sentence to proper Chinese though, can be quite a headache for a non-native speaker of the language. As we have said already, we cannot translate it literally, as it would not work well in standard Chinese; so the sentence “茶被各地人喝 (cha bei gediren he)" has to be considered wrong. A better translation would be “世界各地人们都喝茶 (Shijian gedirenmen dou hecha", which uses the active voice to express the same meaning but uses a different grammatical structure to convey it. Another sentence we can take as example is the following:

a. picnics are held when the weather is nice.

The subject is picnics, are held the predicate, and weather the object. Using the active voice in English would result in the following sentence "When the weather is nice people hold picnics", which uses the object people to complete the sentence in the active voice. As seen in the previous sections, the passive voice in English does not require any specification, so it can be either indirect and intransitive. In Chinese the same sentence would become “天气好野餐被聚 (Tianqi hao yecan bei ju)” which once again does not work in Chinese. A more complete 
translation would be “天公作美时可以聚野餐 (Tiangongzuomei shi keyi ju yecan)", which once again uses the active form instead of the passive.

In some cases, though, active and passive voices are the same in both languages. A good example of this is the sentence "My bag was stolen by a thief” that translates in “我的包被小偷拿 走了 (wode bao bei xiaotou nazoule)". These occurrences are though really rare, since the Chinese language prefers the use of the active voice over the passive and the passive form is mostly only used for misfortunes, negative matters and bad times.

\section{Translating the Chinese passive voice into English}

While translating the English passive voice to Chinese may be difficult, translating the Chinese passive form into English is more direct. The sentence “我被老师批评了（wo bei laoshi pipingle" directly translates to "I was reprimanded by the teacher" ; word by word 我 (wo) I, 被 (bei) passive co-verb, 老 师 (laoshi) teacher, 批评了 (piping + completed action particle le) reprimanded. The only thing native speakers of Chinese should pay attention to, is to remember to place the object of the sentence, in this case teacher, after the verb when translating in English, to avoid production of unnatural language; e.g. "I by the teacher was reprimanded."

\section{CONCLUSION}

This study analyzed how English and Chinese behave when it comes to their active and passive voices respectively. The main purpose of this analysis has been to understand how and when to translate an active voice into another active and when to convert the sentence to better convey the meaning of such sentence into the language in being translated into. English, as an Indo-European language follows a set of rules that are not found in Chinese and vice versa. Is it then the language users' job to have a better understanding of the fundaments of the two languages when it comes to translation, as well as to find solutions to the problems that might arise, whether it is for everyday life matters or professional reasons.

\section{Finding of this study}

The present study described how English uses the passive in 6 specific situations: 1) the actor of an action is unknown; 2) the actor is irrelevant; 3 ) the interlocutor wants to be vague about something or someone; 4) the main topic of the conversation is a general truth or common knowledge; 5) the interlocutor wants to emphasis the specific person or thing acted on; and 6) the passive voice is used in the scientific genre as a standard. These six reasons do not happen in Chinese, therefore transporting this feature of the English language to Chinese leads to inappropriate use of the passive voice in Chinese. In Chinese, on the other hand, the passive voice is mainly used to talk about negative matters, therefore when Chinese speakers use the passive form in English, they are bound to use it for negative matters as they would in Chinese. The present paper has found that when translating from English to Chinese, speakers are bound to transfer their L1 (first language) pragmatics onto L2 (second language), creating wrong language that leads to communication issues. This issue can be dealt with by reinforcing L2 pragmatics when studying Chinese; by doing so learners of Chinese will be less prone to make mistakes when using the passive voice in Chinese. Despite both groups have difficulties translating from a passive voice to the other, this paper argues how more difficult this can be for speakers of English when use the Chinese passive; this is because the English language uses the passive voice extensively and for various situations. The same cannot be said for Chinese speakers, who mainly happen to have difficulties composing the passive form correctly the few times they use it. Since Chinese does not use the passive voice as extensively as English, Chinese speakers are likely to simply use the active voice instead of the passive, unless it is for a negative matter.

\section{Suggestions for future research}

Despite what this study has highlighted, some questions are still yet to be answered. Future research could conduct a comparative study with participants, where researchers ask to translate speakers of both English and Mandarin to translate passive sentences in both languages. Questions on whether proficiency plays a role on passive composition could be also investigated further. Further research on pragmatics of both passive forms would also be beneficial.

\section{REFERENCES}

[1] Aarts, Bas; Haegeman, Liliane (2006). "6. English Word classes and Phrases". In Aarts, Bas; McMahon, April (eds.). The Handbook of English Linguistics. Blackwell Publishing Ltd.

[2] Alexander M. Baratta. Revealing stance through passive voice[J]. Journal of Pragmatics,2008,41(7).

[3] Baskin T I. Hazards of the passive voice.[J]. Nature,1996,381(6585).

[4] Bohner G. Writing about rape: use of the passive voice and other distancing text features as an expression of perceived responsibility of the victim.[J]. British Journal of Social Psychology,2002,40(Pt 4).

[5] Christy N P. Use of the passive voice.[J]. JAMA: The Journal of the American Medical Association,1985,253(2).

[6] Corson, T., \& Smollett, R. (n.d.). Passive Voice: When to Use It and When to Avoid It. Retrieved from https://advice.writing.utoronto.ca/revising/passive-voice/

[7] Dr., M., \& Rockowitz , A.C. GRAMMAR AND MECHANICS Active and Passive Voice. New York: Writing Center, Hunter College, City University of New York.

[8] Eva, Z. (2016). ENGLISH AS A LIGUA FRANCA: THEORY AND PRACTICAL IMPLICATIONS.

[9] Geoffrey K. Pullum. "The passive in English". Language Log.

[10] Gunderman Richard B,Steinmeyer Laura A. The passive voice.[J]. Academic radiology,2015,22(9).

[11] Jia Deng. How to Teach Passive Voice in Chinese ESL classrooms[A]. Information Engineering Research Institute, 2013:5.

[12] Johnson-Laird $P \mathrm{~N}$. The choice of the passive voice in a communicative task.[J]. British journal of psychology (London, England : 1953), 1968,59(1).

[13] Johnson-Laird P N. The interpretation of the passive voice.[J]. The Quarterly journal of experimental psychology,1968,20(1).

[14] Luke, M., Perfors, A., \& Navarro, D. (2010). Read Hamlet in Modern English: Act 1, Scene 3Why are some word orders more common than others? A uniform information density account. Adelaide, South Australia: School of Psychology, University of Adelaide.

[15] Massoumeh HajizadehRivandi,Sulia Masturina Che Razali,Nurhayati Husin,Razifa Mohd Razlan,Nur Hafizah Rabi'ah Husin,Nurul Amilin Razawi. The Correct Use of Passive Voice in Report Writing by Somali SPACE Students in UTM[J]. Procedia Social and Behavioral Sciences,2012,56. 
[16] O'Grady, William, John Archibald, Mark Aronoff, and Janie Rees-Miller (eds.) (2001). Contemporary Linguistics: An Introduction Fourth edition. Boston: Bedford/St. Martin's. ISBN 0-312-24738-9

[17] Richard B. Gunderman,Laura A. Steinmeyer. The Passive Voice[J]. Academic Radiology,2015,22(9).

[18] Z. Liu, Y. Jin, (2011). 2011 7th International Conference on Natural Language Processing and Knowledge Engineering. Piscataway: IEEE.

[19] Zhiying Liu, Yaohong Jin. The research of passive voice in Chinese-English patent machine translation[P]. Natural Language Processing andKnowledge Engineering (NLP-KE), 2011 7th International Conference on,2011. 